\title{
Evaluation of nurse triage in a British accident and emergency department
}

\author{
Steve George, Susan Read, Linda Westlake, Brian Williams, Alistair Fraser-Moodie, Paul Pritty
}

\begin{abstract}
Objective-To compare formal nurse triage with an informal prioritisation process for waiting times and patient satisfaction.

Setting-Accident and emergency department of a district general hospital in the midlands in 1990.

Design-Patients attending between 800 am and $900 \mathrm{pm}$ over six weeks were grouped for analysis according to whether triage was operating at time of presentation and by their degree of urgency as assessed retrospectively by an accident and emergency consultant.
\end{abstract}

Patients - 5954 patients presenting over six weeks.

Main outcome measures-Time waited between first attendance in the department and obtaining medical attention, and patient satisfaction measured by questionnaire.

Results-Complete data on waiting time were collected on 5037 patients $(85 \%)$. Only 1213 of the $2515(48 \%)$ patients presenting during the triage period were seen by a triage nurse. Patients in the triage group waited longer than those in the no triage group in all four retrospective priority categories, though differences were significant for only the two most urgent categories (difference in median waiting time $10.5(95 \%$ confidence interval 3.5 to 14$) \mathrm{min}$ for category 1 and 8.5 ( 3 to 12 ) min for category 2 ). Responses to the patient satisfaction questionnaire were similar in the two groups except for the question relating to anxiety relating to pain.

Conclusions - This study fails to show the benefits claimed for formal nurse triage. Nurse triage may impose additional delay for patient treatment, particularly among patients needing the most urgent attention.

\section{Introduction}

In response to rising attendance figures over the past two decades ${ }^{1}$ about half of the accident and emergency departments in England and Wales prioritise those who attend by degree of urgency (Department of Health, unpublished report). ${ }^{2}$ Nurse triage refers to the formal process of assessment of accident and emergency patients on arrival by a trained nurse, to ensure that they receive appropriate attention with the requisite degree of urgency. ${ }^{34}$ It is claimed that nurse triage results in an overall reduction in waiting time, ${ }^{5-12}$ particularly for those in need of the most urgent attention, and a reduction in levels of anxiety of patients or those accompanying them. ${ }^{13} 14$

In the recent patient's charter the standard relating to waiting time for initial assessment in accident and emergency departments states "that you will be seen immediately and your need for treatment assessed." 15 This could be interpreted to mean that departments not already running formal nurse triage schemes should institute them. In America, however, formal triage schemes have been shown to add $5-10 \%$ to departmental costs, ${ }^{1617}$ and informal prioritisation by a combination of staff takes place already in many British departments (Department of Health, unpublished report). We decided to assess whether formal prioritisation had measurable benefits over existing schemes of informal prioritisation.

\section{Subjects and methods}

The study was conducted in the accident and emergency department of a midland district general hospital with more than 60000 new attendances annually. Nurse triage was practised for five years preceding our 1990 study.

Piloting suggested a study period of six weeks. Originally we divided this into six seven day periods and allocated them alternately as triage and no triage weeks. However, lack of a triage nurse on six half day shifts within weeks allocated to triage necessitated their redesignation as no triage shifts. Triage was then run instead on the corresponding half day shifts of the following no triage weeks, thereby ensuring that an equal number of comparable half days were allocated to each study group.

We recruited all patients attending between $800 \mathrm{am}$ and $900 \mathrm{pm}$ except those attending by appointment (for example, to fracture clinics) or by previous arrangement for admission as inpatients. We grouped patients for analysis according to the regimen operating during the half day shift in which they presented.

Patients in the triage group were assessed on arrival by a trained triage nurse and formally assigned to one of four treatment categories according to urgency before proceeding to reception. Patients in the no triage group were assessed informally by a combination of nursing staff after booking in at reception.

The degree of urgency of treatment for each patient was assessed retrospectively from the clinical record by one of two consultant accident and emergency clinicians, who were blind to whether an individual patient had been triaged or not. They placed patients into one of four priority categories $(1=$ most urgent, $4=$ least urgent). These categories were used as a standard for the purposes of analysis to ensure similar case mix in the two study groups.

For each patient attending we measured the time between first attendance in the department and seeing the doctor. We compared median waiting times in the two study groups for patients in each priority category and tested differences using a Mann-Whitney U test. We calculated $95 \%$ confidence intervals for differences in the median waiting times using the method described by Nicholl ( $\mathrm{J}$ P Nicholl, meeting of International Society of Clinical Biostatistics, Maastricht, September 1989).

A sample of patients received a piloted patient satisfaction questionnaire containing 14 items relating to the patient's opinion of the time waited in the department, inconvenience suffered, anxiety experienced, and the level of information received during the visit. ${ }^{18-21}$ We stratified the sample on the basis of the priority categories assigned to patients by the two clinicians. Questionnaires were dispatched within a week of attendance and reminders and duplicate questionnaires within a further two weeks. Differences in responses between the two study groups were analysed by $\chi^{2}$ tests.
Correspondence to: Dr George. 


\begin{tabular}{|c|c|c|c|c|c|c|c|c|}
\hline \multirow[b]{3}{*}{ Age group } & & & \multicolumn{6}{|c|}{ Incomplete data on waiting time } \\
\hline & \multicolumn{2}{|c|}{$\begin{array}{l}\text { Complete data on waiting time } \\
\qquad(\mathrm{n}=5037)\end{array}$} & \multicolumn{2}{|c|}{$\begin{array}{l}\text { Time saw doctor not recorded } \\
\qquad(\mathrm{n}=566)\end{array}$} & \multicolumn{2}{|c|}{$\begin{array}{l}\text { Did not wait to be seen } \\
\qquad(\mathrm{n}=201)\end{array}$} & \multicolumn{2}{|c|}{$\begin{array}{l}\text { Record card missing } \\
\qquad(\mathrm{n}=150)\end{array}$} \\
\hline & $M$ & F & M & $\mathrm{F}$ & $M$ & $\mathrm{~F}$ & $M$ & $\mathbf{F}$ \\
\hline $0-14$ & 689 & 469 & 100 & 40 & 19 & 6 & & 1 \\
\hline $15-24$ & 787 & 378 & 101 & 32 & 48 & 16 & & \\
\hline $25-34$ & 688 & 272 & 75 & 23 & 30 & 17 & & \\
\hline $35-44$ & 366 & 160 & 37 & 16 & 25 & 7 & & \\
\hline $45-54$ & 241 & 152 & 25 & 17 & 13 & 6 & & \\
\hline $55-64$ & 169 & 142 & 31 & 20 & 6 & & & 2 \\
\hline $65-74$ & 100 & 147 & 15 & 13 & 3 & 1 & & \\
\hline $75-84$ & 64 & 127 & 4 & 11 & & 1 & & \\
\hline$\geqslant 85$ & 18 & 51 & 2 & 4 & 1 & & & \\
\hline Age missing & 9 & 8 & & & $i$ & 1 & 85 & 61 \\
\hline All ages & 3131 & 1906 & 390 & 176 & 146 & 55 & 85 & 64 \\
\hline
\end{tabular}

*Sex was not recorded in one case.

\section{Results}

We collected data on 5954 patients attending over the six weeks. Table I shows the age and sex of the study population. We obtained complete waiting time data on 5037 of the 5954 patients $(84 \cdot 6 \%)$. Fortuitously, 2515 attended during triage periods and 2522 during no triage periods. Despite triage having been run on each half day assigned to it only $1213(48 \%)$ of those attending during triage periods were actually assessed by a triage nurse. Table II compares the allocation of urgency of the triage nurse with that of the clinician in those 1213 patients and shows that patients' conditions often seem more urgent at presentation than in retrospect.

Table III gives the distribution of cases among retrospective priority categories. A significant difference in the overall distribution existed between the triage and no-triage groups. We identified no systematic

TABLE II-Distribution by urgency of 1213 patients assessed both prospectively by a triage nurse and retrospectively by an accident and emergency consultant

\begin{tabular}{lcrrrr}
\hline & \multicolumn{3}{l}{ Priority category assigned by consultants } & \\
\cline { 2 - 5 } $\begin{array}{l}\text { Treatment category } \\
\text { assigned by triage } \\
\text { nurse }\end{array}$ & $\begin{array}{c}1 \\
\text { (Most } \\
\text { urgent) }\end{array}$ & 2 & 3 & $\begin{array}{c}4 \\
\text { (Least } \\
\text { urgent) }\end{array}$ & Total \\
\hline 1 (Most urgent) & 11 & 46 & 32 & 2 & 91 \\
2 & 12 & 186 & 252 & 19 & 469 \\
3 & 1 & 73 & 364 & 123 & 561 \\
4 (Least urgent) & 0 & 4 & 54 & 34 & 92 \\
\hline Total & 24 & 309 & 702 & 178 & 1213 \\
\hline
\end{tabular}

TABLE III - Number (percentage) of patients in each priority category presenting during triage and no triage periods

\begin{tabular}{lcrr}
\hline $\begin{array}{l}\text { Retrospective priority } \\
\text { category }\end{array}$ & $\begin{array}{c}\text { No }(\%) \text { during } \\
\text { triage }\end{array}$ & $\begin{array}{c}\text { No(\%) during } \\
\text { no triage }\end{array}$ & \multicolumn{1}{c}{ Total } \\
\hline 1 (Most urgent) & $70(2 \cdot 8)$ & $109(4 \cdot 3)$ & $179(3 \cdot 6)$ \\
2 & $675(26 \cdot 8)$ & $644(25 \cdot 5)$ & $1319(26 \cdot 2)$ \\
3 & $1424(56 \cdot 6)$ & $1437(57 \cdot 0)$ & $2861(56 \cdot 8)$ \\
4 (Least urgent) & $346(13 \cdot 8)$ & $332(13 \cdot 2)$ & $678(13 \cdot 5)$ \\
\hline Total & $2515(100 \%)$ & $2522(100 \%)$ & $5037(100 \%)$ \\
\hline
\end{tabular}

$\gamma^{:}=9 \cdot 57, \mathrm{df}=3 ; \mathrm{p}=0.0226$.

TABLE IV - Median waiting time (minutes) by study group and by retrospective priority category

\begin{tabular}{|c|c|c|c|c|c|}
\hline \multirow[b]{2}{*}{$\begin{array}{l}\text { Retrospective } \\
\text { priority } \\
\text { category }\end{array}$} & \multicolumn{3}{|c|}{ Median waiting time (minutes) } & \multirow[b]{2}{*}{$\begin{array}{l}\text { Significance of } \\
\text { difference } \\
\text { (Mann-Whitney } \\
\text { U test) }\end{array}$} & \multirow[b]{2}{*}{$\begin{array}{l}95 \% \text { Confidence } \\
\text { interval for } \\
\text { difference }\end{array}$} \\
\hline & $\begin{array}{l}\text { Triage } \\
\text { group } \\
(\mathbf{n}=2515)\end{array}$ & $\begin{array}{l}\text { No triage } \\
\text { group } \\
(n=2522)\end{array}$ & $\begin{array}{l}\text { Difference } \\
\text { (triage minus } \\
\text { no triage) }\end{array}$ & & \\
\hline 1 (Most urgent) & $26 \cdot 5$ & 16 & $10 \cdot 5$ & 0.02 & $3 \cdot 5$ to 14 \\
\hline 2 & 46 & $37 \cdot 5$ & $8 \cdot 5$ & 0.001 & 3 to 12 \\
\hline 3 & 58 & 55 & 3 & $0 \cdot 39$ & -2 to 8 \\
\hline 4 (Least urgent) & 66 & 62 & 4 & $0 \cdot 25$ & $-9 \cdot 5$ to 13 \\
\hline
\end{tabular}

TABLE $\mathrm{v}-$ Responses to patient satisfaction questionnaire among 707 patients presenting during triage and no triage periods

\begin{tabular}{|c|c|c|c|}
\hline & $\begin{array}{l}\text { No (\%) in } \\
\text { triage group } \\
(\mathrm{n}=342)\end{array}$ & $\begin{array}{l}\text { No }(\%) \text { in } \\
\text { no triage } \\
\text { group } \\
(n=365)\end{array}$ & $\begin{array}{l}\text { p Value for } \\
\text { difference } \\
\text { (by } \chi^{2} \text { test) }\end{array}$ \\
\hline \multicolumn{4}{|l|}{ Time waited to book in was: } \\
\hline Shorter than expected & $131(38)$ & $136(38)$ & \multirow{6}{*}{$0 \cdot 83$} \\
\hline About right & 149 (44) & $160(45)$ & \\
\hline Longer than expected & 47 (14) & 44 (12) & \\
\hline Much too long & 14 (4) & 19 (5) & \\
\hline Total responses & $341(100)$ & $359(100)$ & \\
\hline Missing responses & 1 & 6 & \\
\hline \multicolumn{4}{|l|}{ Time waited to see doctor was: } \\
\hline Shorter than expected & $73(21)$ & $73(20)]$ & \multirow{6}{*}{$0 \cdot 08$} \\
\hline About right & $101(30)$ & $108 \quad(30)$ & \\
\hline Longer than expected & $98(29)$ & $81 \quad(22)$ & \\
\hline Much too long & $69(20)$ & $99(27)$ & \\
\hline Total responses & $341(100)$ & $361(100)$ & \\
\hline Missing responses & 1 & 14 & \\
\hline \multicolumn{4}{|c|}{ Inconvenience was suffered due to: } \\
\hline Absence from work & $59 / 289(20)$ & $75 / 305(25)$ & $0 \cdot 26$ \\
\hline Absence from home & $112 / 306(37)$ & $126 / 329(38)$ & 0.72 \\
\hline Missing social engagement & $23 / 271(8)$ & $35 / 295(12)$ & $0 \cdot 24$ \\
\hline \multicolumn{4}{|l|}{ Anxiety was experienced due to: } \\
\hline Absence from work & $53 / 272(19)$ & $52 / 287(18)$ & 0.75 \\
\hline Absence from home & $95 / 287(33)$ & $106 / 311(34)$ & $0 \cdot 87$ \\
\hline Missing social engagement & $16 / 265(6)$ & $27 / 286(9)$ & $0 \cdot 18$ \\
\hline Nature of illness or injury & $171 / 291(59)$ & $194 / 314(62)$ & 0.50 \\
\hline Pain due to illness or injury & $145 / 291(50)$ & $178 / 306(58)$ & 0.05 \\
\hline Long term effects of illness & $113 / 282(40)$ & $126 / 297(42)$ & 0.62 \\
\hline \multicolumn{4}{|l|}{ Information was received about: } \\
\hline Probable waiting time & $102 / 317(32)$ & $114 / 337(34)$ & 0.67 \\
\hline Nature of treatment & $102 / 314(32)$ & $122 / 342(36)$ & 0.44 \\
\hline Nature of illness or injury & $102 / 320(32)$ & $98 / 334(29)$ & 0.54 \\
\hline
\end{tabular}

reason for this and assume it to be a chance finding. However, it necessitates the comparison of waiting times between the two study groups within retrospective priority categories only.

Table IV gives the analysis of waiting times and shows that patients in the triage group waited longer in all four categories than those in the no triage group, although differences were significant only in the two most urgent categories.

We sent out 980 patient satisfaction questionnaires and received $707(72 \%)$ replies after one reminder. Table $\mathrm{V}$ shows the responses to some of the questions. The two groups responded significantly differently only to the question about anxiety related to pain.

\section{Discussion}

Our study failed to show the benefits claimed for nurse triage. Indeed triage extended waiting times, particularly in those requiring the most urgent attention, and patient satisfaction was similar in triaged and non-triaged groups. Our study may reflect only local practice, but similar results have been obtained elsewhere in Britain ${ }^{12}$ and abroad, ${ }^{6}$ although surprisingly the authors of these studies continued to advocate formal nurse triage. ${ }^{1222}$

Only $48 \%$ of patients presenting during the triage periods were assessed by the triage nurse. Since during piloting we recovered $90 \%$ of assessment forms we do 
not believe that this is due to missing forms. Possible reasons include lack of cover for meal and other breaks and some patients bypassing the triage station during busy periods.

Health authorities must purchase health care for their resident populations based on need and cost effectiveness of care. Formal nurse triage schemes add to the costs of accident and emergency departments but may not yield commensurate benefits. Without question, some form of prioritisation will benefit patients in most urgent need of care, but does it need to be formalised and called "nurse triage?"

We thank the medical, nursing, and administrative staff of Derbyshire Royal Infirmary and particularly Janice Glasgow and Tony Potter for their enthusiastic cooperation and tolerance; Lesley Thorpe, research coordinator, for data collection; $\mathrm{Mr}$ Jon Nicholl for statistical advice; and $\mathrm{Dr}$ Gillian Spencer, Dr Philip Milner, and Dr Paul Silcocks for their comments on the manuscript. The work was funded by the Department of Health, which with Trent Regional Health Authority maintains the Medical Care Research Unit. The views expressed in this paper, however, are those of the authors alone.

1 Milner PC, Nicholl JP, Williams BT. Variation in demand for accident and emergency departments in England and Wales 1975-85. F Epidemiol Community $H$ ealth $1988 ; 42: 274-8$.

Pledge MN, Rock D. Priorities of care for the walking wounded. Portsmouth

Portsmouth and South East Hampshire Health Authority, 1988.

3 Rund DA, Rausch TS. Triage. St Louis: Mosby, 1981.
4 Estrada E. Triage systems. Nurs Clin North Am 1981;16:13-24.

Beach L. Paediatric emergency services triage. Fournal of Emergency Nursing $1981 ; 7: 50-5$

6 Shields JE. Making triage work: the experience of an urban emergency department. Fournal of Emergency Nursing 1976;2:37-41.

7 Slater R. Triage nurse in the emergency department. Am f Nurs 1970;70. $127-9$.

8 Nuttall M. The chaos controller. Nursing Times 1986;82:66-8.

8 Nuttall M. The chaos controller. Nursing Times 1986;82:66-8.
9 Bailey A, Hallam K, Hurst K. Triage on trial. Nursing Times 1987;83:65-6.

10 Grose A. Triage in accident and emergency. The Professional Nurse 1988;3: Grose A.
$400-2$.

11 Maidens S. East Surrey triage success. Nursing Standard 6 Feb 1988:18.

12 Mallet J, Woolwich C. Triage in accident and emergency departments. f Adv Nurs 1990;15:1443-51.

13 Wright R. Hostility in accident and emergency departments. Nursing Mirror 1985;161:42-4.

14 McMillan JR, Younger MS, DeWine LC. Satisfaction with hospital emergency department as function of patient triage. Health Care Management Review 1986;11:21-7.

15 Department of Health. The patient's charter. London: HMSO, 1991.

16 Mills J, Webster AL, Wofsy CB, Harding P, D'Acuti D. Effectiveness of nurse triage in the emergency department of an urban county hospital. fournal of the American College of Emergency Physicians 1976;6:877-82.

17 DeAngelis $\mathrm{C}, \mathrm{McHugh} \mathrm{M}$. The effectiveness of various health personnel as triage agents. $\mathcal{F}$ Community Health 1977;2:268-77.

18 Locker $\mathrm{D}$, Dunt $\mathrm{D}$. Theoretical and methodological issues in sociological studies of consumer satisfaction with medical care. Soc Sci Med 1978;12: 283-92.

19 Lebow JL. Consumer assessments of the quality of medical care. Med Care 1974;12:328-37.

20 Ware JE. Effects of acquiescent response set on patient satisfaction ratings. Med Care 1978;16:327-36.

21 Buckles E. Evaluation of patient satisfaction in accident and emergency. Nursing Standard 1990;4:33-5.

22 George SL, Westlake L, Read S, Williams BT. Janforum: feedback-debate about triage in accident and emergency departments (critique). $\mathcal{F}$ Adv Nurs 1991;16:1391.

(Accepted 24 January 1991)

\author{
A F Travers, E Burns, N D Penn, S C Mitchell, G P Mulley
}

\section{Abstract}

Objective-To assess the quality of toilet facilities available for disabled people in a large provincial teaching hospital.

Design-Survey of toilet facilities for patients on the wards and in the outpatient department.

Setting-Teaching hospital in Leeds.

Results-Although the quality of toilet facilities varied, none met the standards recommended by the British Standards Institution. The worst facilities were found on a ward accommodating elderly patients, where the toilets were unsuitable for use by disabled people and bedside commodes had to be used instead.

Conclusion-Toilet provision within a major hospital failed to meet standards required for disabled people. Admission to hospital may therefore result in loss of independence and dignity. If hospitals are to be centres of excellence, greater consideration must be given to the requirements of disabled people in the design of new wards, and current inadequate facilities should be upgraded.

Rehabilitation Research

Unit, School of Medicine, Leeds LS2 9NZ

A F Travers, senior registrar

\section{St James's University}

Hospital, Leeds LS9 7TF

E Burns, senior registrar

S C Mitchell, senior registrar G P Mulley, professor of medicine of the elderly

General Infirmary, Leeds LS1 3EX

N D Penn, senior registrar

Correspondence to:

Dr Travers.

BMf 1992;304:878-9

\section{Introduction}

One in seven adults in the United Kingdom has at least one disability. ${ }^{1}$ The prevalence of disability is probably even higher in hospital patients. One problem often cited by disabled people is that of access to toilets. ${ }^{2}$ Without optimum facilities in hospital, disabled people may be made uncomfortable, embarrassed, and unnecessarily dependent on nurses. We report a study of toilet facilities of a provincial teaching hospital.

\section{Method}

We surveyed the patients' toilets in 13 wards and the outpatient department. The wards assessed were geriatric, psychogeriatric, medical, rheumatological, neurological, orthopaedic, and general surgical. Every medical, surgical, and orthopaedic ward was similarly designed, so only one of each specialty was inspected. The psychogeriatric, rheumatological, and neurological wards were the only wards of their respective specialties. The geriatric wards were of various ages and designs, so each was surveyed.

Comparisons were made with British Standards for access for disabled people to buildings. ${ }^{3}$ On most wards only the toilet the nurses recommended for disabled patients was inspected; the ward toilets not surveyed were likely to be worse in terms of accessibility and equipment. On one ward four toilets were surveyed to assess variability in standards.

\section{Results}

Seventeen toilets were surveyed. The findings and the features of the ideal ward toilet ${ }^{34}$ are presented in the table.

The four toilets surveyed on the same ward were similar in number and type of substandard features.

\section{Discussion}

A hospital environment excelling in the provision of appropriate equipment would promote comfort and independence and demonstrate to patients the range of aids and appliances available to enable them to maintain independence in the community.

None of the toilets surveyed met British Standards, although the rheumatology ward came closest. The worst toilet was on a geriatric ward. It was neither signposted nor labelled. It measured only $1.5 \mathrm{~m}$ by $0.9 \mathrm{~m}$ and the door was only $70 \mathrm{~cm}$ wide. The washbasin could not be reached from the toilet seat, which was one of the lower ones $(43 \mathrm{~cm})$. There were no toilet or 